\title{
Características biométricas de frutos e sementes de Oenocarpus bataua Mart. com procedência de Almeirim, Pará
}

\section{Biometric characteristics of fruits and seeds Oenocarpus bataua Mart. with Almeirim of origin, para}

\author{
Sandra Alves Felizardo ${ }^{1}$, Alessandra Doce Dias de Freitas ${ }^{2}$, Niandro de Souza Marques $^{3}$, Delziane Araújo Bezerra ${ }^{4}$
}

\begin{abstract}
RESUMO - O patauá é uma palmeira pertencente à família botânica Arecaceae. A exploração deste tem como maiores potencialidades a produção de óleo vegetal. A biometria dos frutos é utilizada para verificar a variabilidade genética dentro de populações de uma mesma espécie e as relações desta com os fatores ambientais, além disso, pode contribuir para a tecnologia de produção de mudas de espécies nativas. Desse modo, este trabalho teve por objetivo determinar as principais características biométricas de frutos e sementes, além do peso e do grau de umidade Oenocarpus bataua Mart. com procedência de Almeirim, Pará. O experimento foi conduzido no Laboratório de Tecnologia da Universidade Federal do Pará, Faculdade de Engenharia Florestal, Campus de Altamira. Os frutos foram colhidos maduros de matrizes selecionadas. A análise dos dados foi realizada com o programa Microsoft Excel e o BIOESTAT 5.0. O comprimento e o diâmetro dos frutos e o comprimento e o diâmetro das sementes em estudo tiveram médias de $35,18 \mathrm{~mm}$ e $20,10 \mathrm{~mm} ; 33,1 \mathrm{~mm}$ e $16,9 \mathrm{~mm}$, respectivamente. A massa do fruto teve uma média de 9,6 g. Os maiores graus de umidade foram obtidos nos tratamentos com as sementes inteiras. O peso de mil sementes foi 5665 gramas.
\end{abstract}

Palavras-chave - Arecaceae, Oenocarpus bataua Mart., massa, grau de umidade.

\begin{abstract}
The patauá Is a palm tree belongs to the botanical family Arecaceae. The operation of these has the greatest potential to produce vegetable oil. Biometrics fruit is used to verify the genetic variability within populations of the same species and the relationship of this variability with environmental factors also may contribute to the production technology of seedlings of native species. Thus, this study aims to determine the main biometric characteristics of fruits and seeds, in addition to weight and degree of humidity of Oenocarpus bataua with origin of Almeirim, Pará. The experiment was conducted at the Federal University of Pará Technology Laboratory, Faculty of Forestry, Campus de Altamira. The fruits were harvested ripe arrays selected. Data analysis was performed using Microsoft Excel and the BioEstat 5.0. The length and diameter of the fruits and the length and diameter of the seeds in the study had mean 35,18 mm and 20,10 mm; 33,1 mm and 16,9 mm, respectively. The fruit mass, averaged 9,6 g. The high moisture were obtained in treatments with whole seeds. The thousand seed weight was 5665 grams.
\end{abstract}

Keywords: Arecaceae, Oenocarpus bataua Mart., mass, degree of humidity.

\footnotetext{
*Autor para correspondência

Recebido para publicação em 21/09/2015; aprovado em 14/11/2015

${ }^{1}$ Graduanda em Engenharia Florestal, Universidade Federal do Pará, Altamira-PA; E-mail: sandrafelizardo1@ gmail.com

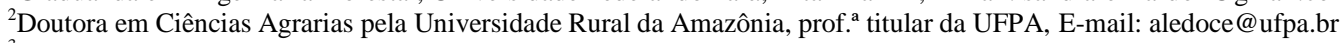

${ }^{3}$ Graduando em Engenharia Florestal, Universidade Federal do Pará, Altamira-PA; E-mail: niandromarques@ hotmail.com

${ }^{4}$ Graduanda em Engenharia Florestal, Universidade Federal do Pará, Altamira-PA; E-mail:, delziane.araujo22@ gmail.com
} 


\section{INTRODUÇÃO}

As palmeiras se destacam dentre os produtos florestais não madeireiros amplamente usados por populações tradicionais por terem importância ecológica e potencial econômico, principalmente em relação à alimentação, medicamentos e construção (GOMES-SILVA et al., 2004).

O patauá (Oenocarpus bataua Mart.) é uma palmeira pertencente à família botânica Arecaceae. Segundo Henderson et al.(1995), ocorre em toda a Amazônia e também na parte sul da região central. No nome do gênero, o patauá tem uma alusão à utilização mais tradicional desta palmeira, a fabricação de sucos (denominados regionalmente de vinhos), de modo que, oinos=vinho e karpos=fruto (BALICK, 1986). Foram os naturalistas quem nomearam quando observaram, há quase dois séculos, a utilização dos frutos dessa palmeira na produção de sucos nutritivos (WALLACE, 1853). Do fruto também se extrai o óleo, considerado um produto substituto do azeite de oliva, por apresentar grande semelhança físico-química e propriedades quase idênticas (BALICK, 1988, 1993).

Essa palmeira tem sua propagação por sementes, que germinam em períodos que variam de 44 a 52 dias após a semeadura. Seus frutos são dispersos principalmente por aves ou mamíferos. No entanto alguns animais podem atuar como predadores como o porquinho e o porcão que destroem as sementes (GOMES-SILVA, 2005).

Os frutos tem um formato redondo-ovalado, possuem epicarpo liso, de cor púrpura, escura, quando maduros; medem de 2,5 a $3,5 \mathrm{~cm}$ de comprimento, na base se conserva uma cúpula endurecida, a qual se forma através do perianto que acompanha o seu crescimento, uma tênue camada cerosa, esbranquiçada, o recobre. Suculento e oleoso é o mesocarpo, apresenta cor branca, verde ou rosada púrpura, mede de 1 a 3 mm de espessura. A semente única contém um endosperma ruminado recoberto por delicadas fibras achatadas e endosperma córneo (BALICK, 1988). Esses frutos servem de alimentos para muitos animais (BALICK e GERSHOFF, 1981), desta forma, são potenciais dispersores, más com alguns podendo atuar como predadores.

A biometria de frutos e sementes é um instrumento utilizado para verificar a variabilidade genética dentro de populações de uma mesma espécie e as relações desta variação com os fatores ambientais (MACEDO et al., 2009).

A descrição e a caracterização biométrica de frutos e sementes podem proporcionar subsídios importantes para a diferenciação de espécies do mesmo gênero, haja vista que espécies arbóreas tropicais apresentam grande variabilidade no tamanho dos frutos, no número de sementes por frutos e no tamanho das sementes (CRUZ, et al., 2001), além disso, pode contribuir para a tecnologia de produção de mudas de espécies nativas (PINÃ-RODRIGUES 2002).

A biometria das sementes também está relacionada com as características de dispersão e com o estabelecimento de plântulas, além de ser utilizada para diferenciar espécies pioneiras e não-pioneiras em florestas tropicais (BASKIN; BASKIN, 1998).

O teor de água exerce forte influência nas propriedades físicas e químicas das sementes florestais, sendo esta determinação muito importante em todas as etapas do processo de tecnologia de sementes, desde a manipulação, o processamento, o armazenamento, entre outras (CARVALHO, 2005).
As sementes de patauá têm comportamento recalcitrante (CARVALHO et al., 2001). Portanto essas sementes que não perdem água acentuadamente no final da maturação, e são dispersas com altos teores de água, não toleram o dessecamento; assim, não podem ser armazenadas por longos períodos, apresentando curta longevidade (PAMMENTER \& BERJAK, 1999).

Apesar da importância faunística, humana e ambiental, essa espécie ainda possui escassas informações. Desse modo, este trabalho teve por objetivo determinar as principais características biométricas de frutos e sementes, além do peso e do grau de umidade de Oenocarpus bataua Mart. com procedência de Almeirim, Pará.

\section{MATERIAL E MÉTODOS}

O experimento foi conduzido no Laboratório de Tecnologia da Universidade Federal do Pará, Faculdade de Engenharia Florestal, Campus de Altamira. Utilizou- se frutos e sementes de patauá com procedência do município de Almeirim - PA.

O clima da região de Almeirim, segundo Köppen, é do tipo Amw, caracterizado como quente e úmido e o mais frio dessa categoria e apresenta duas estações bem definidas, uma chuvosa, de janeiro a julho e outra seca, de agosto a dezembro. A temperatura permanece estável durante o ano inteiro, situando-se na média mensal de 25,5 a $27,4{ }^{\circ} \mathrm{C}$ e a precipitação pluviométrica média anual é de $2.115 \mathrm{~mm}$.

Os frutos foram colhidos maduros de cinco matrizes selecionadas nas comunidades rurais da zona III no final do mês de novembro do ano 2014. Essa zona é composta por cerca de 300 famílias com importantes comunidades extrativistas, cuja característica principal é a agrícola de subsistência e florestal.

Após a coleta, os frutos foram acondicionados em saco de polietileno e transportados ao laboratório. Para a realização do trabalho se utilizou frutos selecionados ao acaso. Determinou-se as principais características biométricas dos frutos e sementes, bem como as suas massas, além da massa da polpa. Também foi determinada a massa das sementes contidas em cada $\mathrm{kg}$.

Pesou-se os frutos com/sem sementes em balança eletrônica de precisão de $0,001 \mathrm{~g}$; obteve-se a massa da polpa através do peso de 100 amostras, subtraiu-se a massa das sementes a essa mesma quantia da massa dos frutos. O cálculo das sementes contidas em cada quilograma foi permitido por conta da determinação da massa de cem sementes. A massa das 100 sementes foi obtida através do peso de oito repetições respeitando a essa mesma quantidade de sementes (BRASIL, 2009).

O grau de umidade foi determinado pelo método da estufa a $105 \pm 3{ }^{\circ} \mathrm{C}$, durante 24 horas, utilizou-se quatro amostras com sementes inteiras úmidas e quatro amostras com sementes úmidas quebradas, cada amostra contendo uma semente. O cálculo do grau de umidade seguiu as regras conforme (BRASIL, 2009).

As características biométricas, comprimento e o diâmetro dos frutos foram mensurados com o auxilio de um paquímetro digital. Considerou-se o eixo longitudinal como o comprimento e o diâmetro em ângulo reto com o eixo anterior na parte mais larga da semente (LEÃO, CARVALHO \& OHASHI, 2001). 
Para os dados obtidos das variáveis comprimentos e massa, foram calculados a média aritmética, valor mínimo e valor máximo, variância, desvio padrão e coeficiente de variação. Para as características biométricas se calculou a distribuição de frequência e gráficos de histogramas. Utilizouse o programa Microsoft Excel 2007 para processamento dos dados. Para calcular a correlação de PEARSON entre fruto e semente e fruto e polpa utilizou-se o programa Bioestat 5.0.

\section{RESULTADOS E DISCUSSÃO}

Na Tabela 01 estão apresentados os dados de biometria dos frutos de Patauá, observa-se que o comprimento e o diâmetro dos mesmos variaram de 30,76 a $37,98 \mathrm{~mm}$ e 17,95 a 22,06 mm, respectivamente. $\mathrm{Na}$ amostragem dos frutos analisados obteve-se uma média de $35,18 \mathrm{~mm}$ de comprimento e 20,10 $\mathrm{mm}$ de diâmetro. Mendonça et al. (2011) ao estudarem frutos de patauazeiros nativos do leste do Acre encontraram valor médio de $34,3 \mathrm{~mm}$ para o comprimento, muito próximo ao encontrado neste trabalho e 24,0 mm para o diâmetro, valor levemente superior ao desta pesquisa.

Tabela 01: Estatística descritiva do comprimento e diâmetro de frutos de patauá.

\begin{tabular}{ccc}
\hline $\begin{array}{c}\text { Medidas } \\
\text { estatísticas }\end{array}$ & $\begin{array}{c}\text { Comprimento } \\
\text { (mm) }\end{array}$ & $\begin{array}{c}\text { Diâmetro } \\
\text { (mm) }\end{array}$ \\
\hline Mínimo & 30,76 & 17,95 \\
Máximo & 37,98 & 22,06 \\
Média & 35,18574257 & 20,1056436 \\
Variância & 1,824774693 & 0,54796683 \\
Desvio Padrão & 1,350842216 & 0,74024782 \\
CV (\%) & 5,016100742 & 2,75284554 \\
\hline
\end{tabular}

Com relação à biometria de sementes, observa-se na Tabela 02 que o comprimento e o diâmetro destas, variaram de 30,84 a $38,85 \mathrm{~mm}$ e 15,4 a $18,31 \mathrm{~mm}$ respectivamente. Com isso se alcançou uma média de $33,1 \mathrm{~mm}$ de comprimento e 16,9 mm de diâmetro. Mendonça et al. (2011) encontraram resultados médios de $28,4 \mathrm{~mm}$ e de $20,8 \mathrm{~mm}$ para o comprimento e diâmetro das sementes respectivamente, o que evidenciou comprimento das sementes menores, no entanto com os diâmetros maiores.

Tabela 02:Estatística descritiva do comprimento e diâmetro da semente de patauá.

\begin{tabular}{ccc}
\hline $\begin{array}{c}\text { Medidas } \\
\text { estatísticas }\end{array}$ & $\begin{array}{c}\text { Comprimento } \\
(\mathbf{m m})\end{array}$ & $\begin{array}{c}\text { Diâmetro } \\
(\mathbf{m m})\end{array}$ \\
\hline Mínimo & 30,84 & 15,4 \\
Máximo & 38,85 & 18,31 \\
Média & 33,10 & 16,91 \\
Variância & 1,46 & 0,35 \\
Desvio Padrão & 1,21 & 0,589 \\
CV (\%) & 4,44 & 2,07 \\
\hline
\end{tabular}

Já para as variáveis massa do fruto, massa da semente e massa da polpa se constatou grande variação, ou seja, elas oscilaram de 7,6 a 11,6 g, de 4,8 a 7,9 g e de 2,7 a 4,0 g respectivamente, com uma média de 9,6 , g 6,4 g e 3,1 g nessa mesma sequência (Tabela 03).
Rodrigues et al. (2005) observaram, em frutos das palmeiras patauá e najá (Maximiliana maripa (Aublet) Drude, ambas da família Arecaceae, encontradas na Amazônia, relação semente/polpa $(1,16$ e 3,57, respectivamente) bastante elevada, caracterizando-os como frutos com baixo teor de polpa.

Brandão e Oliveira (2014) ao avaliar e caracterizar frutos de acessos de patauazeiro conservados no Banco de Germosplasma da Embrapa Amazônia Oriental encontraram peso do fruto que variou de $6,2 \mathrm{~g}$ a $23,5 \mathrm{~g}$, com média de $11,7 \mathrm{~g}$. Valores estes com uma variação bem superior, porém com uma média próxima ao encontrado neste trabalho.

Silva et al. (2011) ao estudar uma espécie do mesmo gênero, bacaba, Oenocarpus balickii Kahn, constataram o peso das sementes com variação entre 0,58-1,14 g, média $=0,89 \mathrm{~g}$ e com $\mathrm{CV}=11,39 \%$, o que evidencia maior variação entre os valores obtidos e a sua média, comparado com o cv da massa da semente de patauá.

Segundo Botezelli e Malavasi (2000) estudos de uma única espécie oriundos de procedências distintas detectam diferenças fenotípicas em relação à variabilidade genética e aos fatores do ambiente, pois possibilita a expressão de determinadas características em ambientes diferenciados.

Tabela 03: Massa do fruto, das sementes e da polpa de patauá.

\begin{tabular}{cccc}
\hline $\begin{array}{c}\text { Medidas } \\
\text { estatísticas }\end{array}$ & $\begin{array}{c}\text { Massa do } \\
\text { fruto (g) }\end{array}$ & $\begin{array}{c}\text { Massa da } \\
\text { semente (g) }\end{array}$ & $\begin{array}{c}\text { Massa da polpa } \\
(\mathbf{g})\end{array}$ \\
\hline Mínimo & 7,64 & 4,89 & 2,70 \\
Máximo & 11,62 & 7,93 & 4,05 \\
Média & 9,59 & 6,44 & 3,15 \\
Variância & 0,66 & 0,37 & 0,067 \\
Desvio & 0,81 & 0,61 & 0,259 \\
Padrão & 6,89 & 5,86 & 2,14 \\
\hline CV (\%) & & & \\
\hline
\end{tabular}

Através do coeficiente de correlação de Pearson (r) ou o r de Pearson que mede o grau da correlação linear entre duas variáveis quantitativas, podemos constatar através dos dados plotados na tabela 04 e figura 01 , que houve uma correlação classificada como forte e positiva, tanto para a relação frutos/sementes, com $\mathrm{r}$ (Pearson) $=0,9719$; como para a relação fruto/polpa com $\mathrm{r}$ (Pearson) $=0,8307$. Assim, para essas amostras de frutos e sementes de patauá em análise, pode-se afirmar que quanto maior é o fruto, maior será a semente e em menor grau, porém bem próximo proporcionalmente, também será maior a massa da polpa.

Moura et al.(2010) ao estudarem frutos e sementes da espécie Butia capitata, observaram que o comprimento e o diâmetro se correlacionaram positivamente com as outras características (Massa fresca do fruto (PFF), Massa fresca da polpa (PFP), Massa seca da polpa (PSP), Massa fresca do pirênio (PFPI) e número de sementes por fruto (NSF), indicando que quanto maior o fruto, maior é a sua massa.

Carrijo (2011) também encontrou para a espécie Syagrus oleracea Becc. uma correlação positiva entre comprimento com diâmetro, razão comprimento/diâmetro e massa e diâmetro e massa de frutos, indicando que ao aumentar uma medida a outra também aumenta. Essas informações são úteis, pois podem auxiliar na indicação ou na classificação de frutos 
com vistas a melhor uniformidade dos mesmos no plantio e para a seleção dos frutos para o beneficiamento industrial.

Goudel (2012) verificou que os frutos de jerivá (Syagrus romanzoffiana Cham.) pesam em média 5,61g, seu peso e tamanho se correlacionam de forma linear, positiva e significativa com o tamanho e peso da semente com endocarpo.

Tabela 04: Dados da correlação de Pearson entre fruto/semente e fruto/polpa de Patauá.

\begin{tabular}{lclc}
\hline \multicolumn{2}{l}{ Correlação fruto e sementes } & \multicolumn{2}{l}{ Correlação fruto e polpa } \\
\hline $\mathbf{n}$ (pares) $=$ & 50 & $\mathbf{n}$ (pares) $=$ & 50 \\
r (Pearson) $=$ & 0.9719 & r (Pearson) $=$ & 0.8307 \\
IC 95\% $=$ & 0.95 a 0.98 & IC 95\%= & 0.72 a 0.90 \\
IC 99\% = & 0.94 a 0.99 & IC 99\%= & 0.67 a 0.92 \\
R2 $=$ & 0.9446 & $\mathbf{R 2}=$ & 0.6901 \\
$\mathbf{t}=$ & 28.6040 & $\mathbf{t}=$ & 10.3388 \\
$\mathbf{G L}=$ & 48 & $\mathbf{G L}=$ & 48 \\
(p) $=$ & $<0.0001$ & $\mathbf{( p )}=$ & $<0.0001$ \\
Poder $\mathbf{0 . 0 5}=$ & 1.0000 & Poder $\mathbf{0 . 0 5}=$ & 1.0000 \\
Poder $\mathbf{0 . 0 1}=$ & 1.0000 & Poder $\mathbf{0 . 0 1}=$ & 1.0000 \\
\hline
\end{tabular}

Figura 01: Correlação de Pearson entre fruto e semente e fruto e polpa.

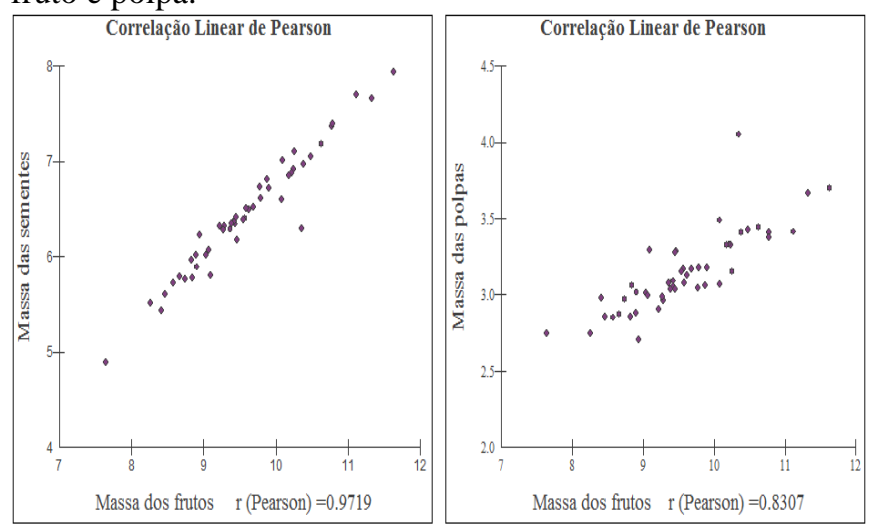

Os resultados das análises do ensaio para a definição do melhor procedimento de preparação das sementes, visando à determinação do teor de umidade, estão apresentados na Tabela 05 , onde observa-se que os maiores graus de umidade foram obtidos nos tratamentos em que as sementes permaneceram inteiras, com uma média de $29,6 \%$.

Nazário e Ferreira (2012) expuseram sementes de patauá às condições do ambiente de laboratório (temperatura de 24,3 ${ }^{\circ} \mathrm{C}$ e UR de $63,6 \%$ ), o que provocou decréscimo progressivo no grau de umidade das mesmas, alcançando os valores de 38,$0 ; 32,1 ; 27,9 ; 24,2 ; 18,4$ e $19,7 \%$, após $0,2,4,6,8$ e 10 dias de dessecamento, respectivamente e concluíram que sementes de patauá são sensíveis ao dessecamento, enquadrando-se dentro do tipo chamado recalcitrante, com os teores de água crítico e letal de $35,0 \%$ e $24,3 \%$, respectivamente.
Tabela 05: Grau de umidade em sementes inteiras e quebradas de Patauá.

\begin{tabular}{ccc}
\hline $\begin{array}{c}\text { Medidas } \\
\text { estatísticas }\end{array}$ & $\begin{array}{c}\text { Grau de umidade } \\
\text { S. inteiras (\%) }\end{array}$ & $\begin{array}{c}\text { Grau de umidade } \\
\text { S. quebradas (\%) }\end{array}$ \\
\hline Mínimo & 28.9161 & 28.37505 \\
Máximo & 30.63723 & 29.97999 \\
Média & 29.61531 & 28.92484 \\
Variância & 0.529512 & 0.550858 \\
Desvio Padrão & 0.727676 & 0.742198 \\
CV (\%) & 1.787968 & 1.904445 \\
\hline
\end{tabular}

A Figura 02 apresenta o comportamento dos frutos e das sementes de patauá quanto a sua distribuição de frequência em relação ao comprimente e ao diâmetro, expressos em função da distribuição destes em dez classes. Para a distribuição de frequência de diâmetros dos frutos a Figura 02A demonstra que $76 \%$ apresentam valores compreendidos entre 19,18 a 20,82 mm. Carrijo (2011) ao estudar frutos e sementes de guariroba (Syagrus oleracaea Becc.) encontrou valores onde a maior parte dos frutos se encontram numa faixa de diâmetro intermediário, variando do ponto médio $2,93(35,2 \%)$ ao ponto médio $3,505(41,5 \%)$.

Para o comprimento dos frutos observa-se na Figura 02B que $71 \%$ deles apresentam valores de $34,29 \mathrm{~mm}$ a 37,12 $\mathrm{mm}$. Silva (2007), relata que a maior frequência de frutos de bacaba (Oenocarpus bacaba Mart.) ocorreu entre 20,5 a 22,5 $\mathrm{mm}$ e 14,0 a $15,0 \mathrm{~mm}$ para o comprimento e espessura, respectivamente.

Para a distribuição de frequência de diâmetro das sementes a Figura 02C aponta para valores de 16,27 a 17,72 $\mathrm{mm}$, perfazendo $82 \%$ destas. Valores inferiores no diâmetro equatorial entre frutos e sementes com endocarpo foram encontrados para Butia capitata, que apresentaram valores médios de $27 \mathrm{~mm}$ para frutos e $14 \mathrm{~mm}$ para sementes com endocarpo (SCHWARTZ et al., 2010).

Já para a distribuição de frequência dos comprimentos das sementes a Figura 02D apresenta uma concentração de $85 \%$ compreendida entre 31,64 a 34,84 mm. Goudel (2012) encontrou para a palmeira jerivá (Syagrus romanzoffiana Cham.) frutos que apresentaram diâmetro longitudinal com maior distribuição ente 21 e $22 \mathrm{~mm}$, enquanto as sementes com endocarpo tiveram maior frequência entre 19 e $20 \mathrm{~mm}$. Gonçalves et al. (2013) ao caracterizarem biometricamente os frutos e sementes de mangaba (Hancornia speciosa Gomes) verificaram que a maioria dos frutos, cerca de $35 \%$, apresentou diâmetro equatorial de 40,30 a 44,36 mm, com limite mínimo e máximo de 32,18 e $56,54 \mathrm{~mm}$ e comprimento longitudinal variando de 41,22 a 45,65 mm, o que representou $40 \%$ do total (maioria). 
Figura 02: Distribuição de frequência dos comprimentos e diâmetros dos frutos e sementes de patauá.
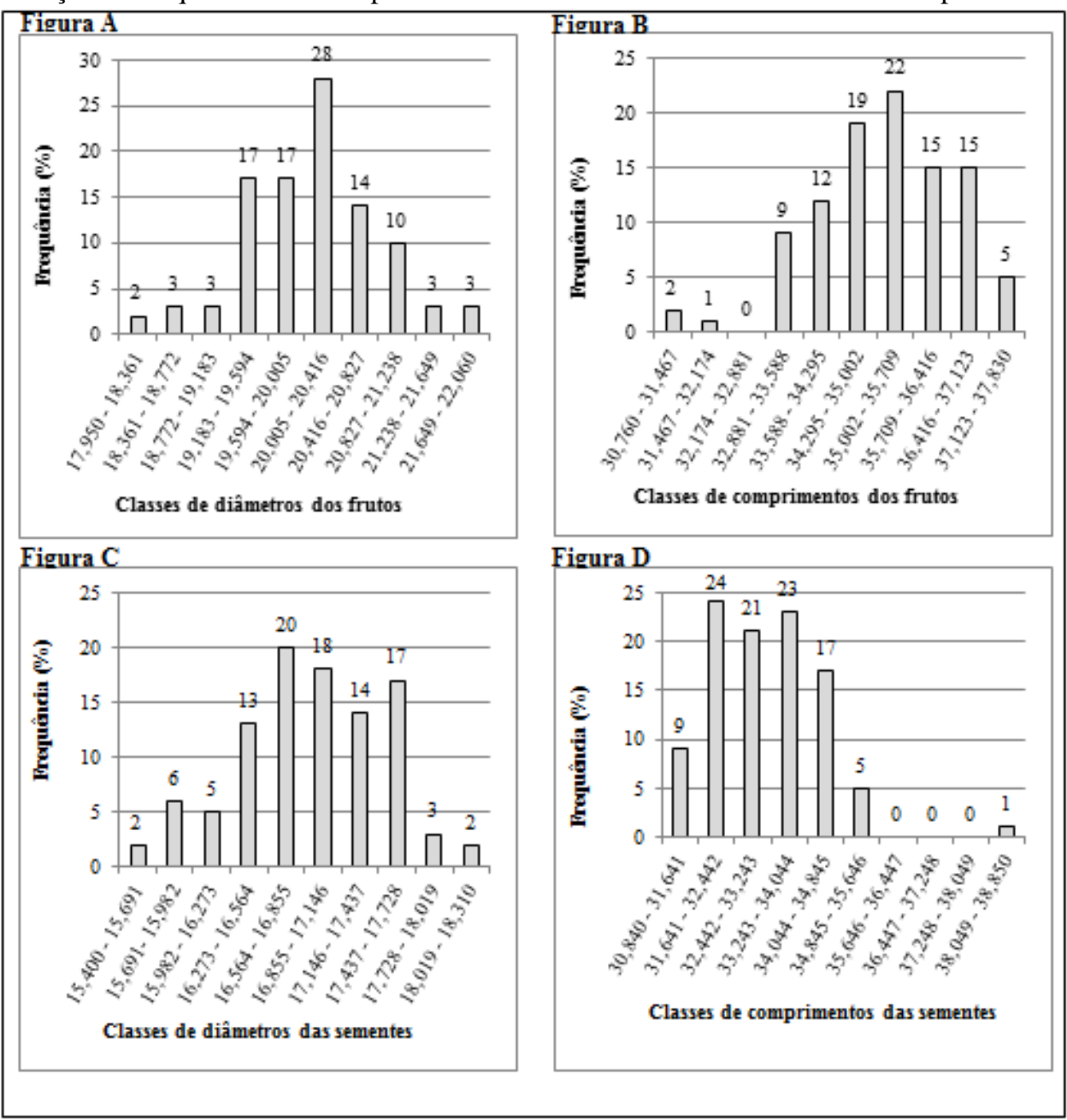

Para o peso de mil sementes conforme preconiza a regra para análise de sementes foram obtidos os resultados especificados na Tabela 06 e ao multiplicar a média por dez, tem-se o valor de 5665 gramas que equivale a mil sementes. Pode-se ainda estimar que 176,5 sementes compõe um quilograma destas. Batista (2009) ao estudar a morfologia de sementes de Syagrus oleracea Becc. (Mart.) (Arecaceae) observou que um quilograma conteve 77 diásporos de guariroba, e o peso de 1000 diásporos foi de 13,08kg.

Oliveira e Bosco (2013) ao estudarem sementes de Copernicia hospital Martius. constataram que o peso de mil sementes do lote analisado foi de $570,6 \mathrm{~g}$.

É comum espécies de palmeiras apresentarem variações individuais para diferentes características, sendo atribuídas, entre outros aspectos, a fatores ambientais e variabilidade genética (MHANHMAD et al., 2011).

Tabela 06: Valores para o cálculo do peso de mil sementes.

\begin{tabular}{lc}
\hline Medidas estatísticas & Peso de cem sementes (g) \\
\hline Mínimo & 552 \\
Máximo & 590 \\
Média & 566,5 \\
Variância & 180,2857 \\
Desvio Padrão & 13,42705 \\
CV (\%) & 2,370177 \\
\hline
\end{tabular}

O tamanho e o peso das sementes podem ser influenciados pelo estágio de maturação dos frutos, fatores genéticos e pelas condições climáticas sob as quais se desenvolve a planta (BATISTA et al., 2011).

\section{CONCLUSÕES}

O comprimento e o diâmetro dos frutos e das sementes de Oenocarpus bataua Mart. tiveram médias de 35,18 mm e 20,10 mm; 33,1 mm e 16,9 mm, respectivamente.

Para a variável massa do fruto, massa da semente e massa da polpa de Oenocarpus bataua Mart. Se encontrou uma média de 9,6 g; 6,4 g e 3,1 g nessa mesma sequência. Além disso, foi constatada uma correlação forte e positiva, tanto para a relação frutos/sementes, com $\mathrm{r}$ (Pearson) $=$ 0,9719; como para a relação fruto/polpa com $r$ (Pearson) $=$ 0,8307 .

Os maiores graus de umidade foram obtidos nos tratamentos com as sementes inteiras. O peso de mil sementes foi 5665 gramas, onde 176,5 sementes compõe um quilograma destas.

\section{REFERÊNCIAS BIBLIOGRÁFICAS}

BALICK, M. J.; GERSHOFF, S. N. Nutricional evaluation of the Jessenia bataua pal: Source of high quality protein and oil from Tropical America. Economic_Botany. New York, v. 35, n.3 p. 261-271, 1981. 
BALICK, M. J. Systematics, and economic botany of the Oenocarpus - Jessenia (Palmae) complex.Adv. Economic Botany, v.3, p.01-140, 1986.

BALICK, M.J. Jessenia and Oenocarpus: neotropical oil palms worthy of domestication. Food and agriculture organization of the United Nations-FAO. In: Plant Prodution and Protection. 191 p. (Paper 88), Rome, 1988.

BALICK, M.J. Patauá. In: CLAY, J. W.; CLEMENT, C. R. (Ed). Selected species and strategies to enhance income generation from Amazonian Forest.Roma: FAO, 1993.p.81-91. Disponível em: <http://www.fao.org/docrep/V0784E/V0784E00.htm>. Acesso em: 27 jun. 2015.

BASKIN, C. C.; BASKIN, J. M. Seeds: ecology, biogeography, and evolution of dormancy and germination. London: Academic Press, 1998.

BATISTA, G. S. Morfologia e germinação de sementes de Syagrus oleracea Becc. (Mart.) Becc (Arecaceae). Dissertação (Mestrado em Agronomia) - Faculdade de Ciências Agrárias e Veterinárias, Universidade Estadual Paulista, Jaboticabal, 46f. 2009.

BATISTA, G. S.; COSTA, R. S.; GIMENES, R.; PIVETTA, K. F. L.; MÔRO, F.V. Aspectos morfológicos dos diásporos e das plântulas de Syagrus oleracea (Mart.) Becc - Arecaceae. Comunicata Scientiae, v. 2, n. 3, p. 170-176, 2011.

BOTEZELLI, L.; DAVIDE, A. C. \& MALAVASI, M. M. Características dos frutos e sementes de quatro procedências de Dipteryx alata Vogel (Baru). Cerne 6(1): 9-18. 2000.

BRANDÃO, C. P.; OLIVEIRA, M. do S. P. Avaliação e caracterização de frutos em patauazeiro. 18Seminário de Iniciação Cientifica e $2^{\circ}$ Seminário de pós-graduação da Embrapa Amazônia Oriental. 2014, Belém-PA.

BRASIL. Ministério da Agricultura, Pecuária e Abastecimento. Teste de germinação. In: Regras para análise de sementes - Brasília: Mapa/ACS, 2009. cap.5, p.147-224. ISBN 978-85-99851-70-8.

CARRIJO, N. S. Germinação e caracterização física e morfológica de frutos e sementes de Syagrus oleracaea Becc.. Dissertação (Mestrado) - Universidade Federal de Goiás, Campus Jataí, 2011.

CARVALHO, J.E.U.; MÜLLER, C.H.; NASCIMENTO, W.M.O. Classificação de sementes de espécies frutíferas nativas da Amazônia de acordo com comportamento no armazenamento. (Embrapa Amazônia. Comunicado técnico, 60, 4p.). Belém: EMBRAPA Amazônia Oriental, 2001.

CARVALHO, N. M. A secagem de sementes. São Paulo: Funep, 2005.
CRUZ, E. D.; MARTINS, F. O.; CARVALHO, J. E. U. Biometria de frutos de jatobá-curuba (Hymenaea intermédia Ducke, Leguminosae-Caesalpinoideae). Revista Brasileira de Botânica 24(2): 161-165. 2001.

GOMES -SILVA, D. A. P.; WADT, L. H. O; EHRINGHAUS, C. Ecologia e manejo de patauá ( Oenocarpus bataua Mart.) para produção de frutos e óleo. Embrapa Acre. Documentos, 88. Rio Branco-AC, 2004.

GONÇALVES, Laissa Gabrielle Vieira; ANDRADE Fabrício Ribeiro; MARIMON JUNIOR, Ben Hur; SCHOSSLER, Thiago Rodrigo; LENZA, Eddie; Marimon, Beatriz Schwantes. Biometria de frutos e sementes de mangaba (Hancornia speciosa Gomes) em vegetação natural na região leste de Mato Grosso, Brasil. Rev. de Ciências Agrárias vol.36 no.1 Lisboa jan. 2013.

GOUDEL, Flora. Caracterização e Processamento de mapuitã, os frutos da palmeira jerivá (Syagrus romanzoffiana Cham.). Dissertação (mestrado) Universidade Federal de Santa Catarina dissertação. Florianópolis, SC, 115 p.; $21 \mathrm{~cm}, 2012$.

HENDERSON, Andrew; GALEANO, Gloria; BERNAL, Rodrigo. Field Guide to the Palms of the Americas. New Jersey: Princeton University Press, 1995.

LEÃO, N. V. M.; CARVALHO, J. E. U.; OHASHI, S. T. Fenologia reprodutiva de 25 espécies arbóreas da Amazônia. In: SILVA, J. N. M; CARVALHO, J. O. P.; YARED, J. A. G. A Silvicultura na Amazônia Oriental: contribuições do Projeto Embrapa/ DFID. Belém: Embrapa Amazônia Oriental: DFID, 2001. p. 139-158.

MACEDO, M. C. DE.; SCALON, S. DE P. Q.; SARI, A. P.; SCALON FILHO, H.; ROSA, Y. B. C. J.; ROBAINA, A. D. Biometria de frutos e sementes e germinação de Magonia pubescens St.Hil (Sapindaceae). Revista Brasileira de Sementes, vol. 31, n. 2, p. 202-211, 2009.

MENDONCA, C. C. ; FERREIRA, E. J. L. ; SILVA, G. M. ; SILVA, A. S. ; BARBOSA, C. S. ; LIMA, A. F. . Biometria dos Frutos e Sementes do Patauá (Oneocarpus bataua Mart.) Nativo da Região Leste do Acre, Brasil.. In: $63^{\circ}$ Reunião Nacional da SBPC, 2011, Goiânia. Anais da $63^{\circ}$ Reunião Anual da SBPC, 2011.

MHANHMAD, S.; LEEWANISH, P.; PUNSUVON, V.; SRINIVES, P. Seasonal effects on bunch components and fatty acid composition in Dura oil palm (Elaeis guineensis). African Journal of Agricultural Research, v. 6, n. 7, p. 1835 - 1843, April, 2011.

MOURA, R. C., LOPES, P. S. N., BRANDÃO JUNIOR, D. S., GOMES, J. G. \& PEREIRA, M. B. Biometria de frutos e sementes de Butia capitata (Mart.) Beccari (Arecaceae), em vegetação natural no Norte de Minas Gerais, Brasil. Biota Neotrop. vol.10, n.2. 2010.

NAZÁRIO, P; FERREIRA, N. S. A. do. Emergência de plântulas de patauá (Oenocarpus bataua Mart.) em 
função do dessecamento das sementes. Informativo ABRATES, vol.22, $n^{o} .1$, 2012. Disponível em: < http://www.abrates.org.br/images/stories/informativos/v 22n1/Artigo_5.pdf. Acesso em: 05 de fevereiro de 2015.

OLIVEIRA, A. B. de; BOSCO, M. R. de O. Biometria, determinação da curva de absorção de água em sementes e emergência inicial de plântulas de Copernicia hospita Martius. Rev. Bras. de Agroecologia. 8(1): 66-74 ISSN: 1980-9735 (2013).

PAMMENTER, N.W.; BERJAK, P.A review of recalcitrant seed physiology in relation to desiccation-tolerance mechanisms. Seed Science Research, v.9. n.1, p.13-37, 1999.

PINÃ-RODRIGUES, F.C.M. Guia prático para a colheita e manejo de sementes florestais tropicais. Rio de Janeiro, IDACO. 2002.

RODRIGUES, A. M. C.; GAMA, S. S.; LINS, R. T.; RODRIGUES, P. R.; SILVA, L.H.M. Estudo da potencialidade de três oleaginosas amazônicas para a produção de biodiesel: biodiesel o novo combustível do Brasil. Belém: Universidade Federal do Pará, Laboratório de Operações de Separação, 2005. p. 345350 .

SCHWARTZ, E.; FACHINELLO, J. C.; BARBIERI, R. L.; SILVA, J. B. da. Avaliação de populações de Butia capitata de Santa Vitória do Palmar. Revista Brasileira de Fruticultura, Jaboticabal, SP, v. 32, n. 3, p.736-745, 2010 .

SILVA, B. M. S. Morfo-anatomia e envelhecimento acelerado em diásporos de Oenocarpus bacaba Mart. Arecaceae. Dissertação (Mestrado em Agronomia) Universidade Estadual Paulista, Jaboticabal, 68f. 2007.

SILVA, G. M. da; FERREIRA, E. J. L.; SILVA, A. S. da; BARBOSA, C. de S.; LIMA, A. F. de; MENDONÇA, C. C. de. Aspectos biométricos dos cachos, frutos e sementes da bacaba-de-caranaí Oenocarpus balickii kahn oriunda do Vale do Rio Juruá, ACRE. $63^{\text {a }}$ Reunião Anual da SBPC. Goiânia, GO, 2011. 